\title{
Increased Adenine Nucleotide Turnover in Duchenne Muscular Dystrophy
}

\author{
TUliO E. BERTORINI, GENARO M. A. PALMIERI, DIANA AIROZO, N. LAWRENCE EDWARDS, \\ AND IRVING H. FOX ${ }^{(42)}$ \\ Departments of Neurology and Medicine, University of Tennessee Center for the Health Sciences and the Human \\ Purine Research Center, Departments of Internal Medicine and Biological Chemistry, University of Michigan, Ann \\ Arbor, Michigan, USA
}

\begin{abstract}
Summary
To investigate a possible disorder of adenine nucleotide turnover in Duchenne muscular dystrophy, we evaluated 15 patients with mild Duchenne muscular dystrophy, eight patients with severe muscular dystrophy, seven patients with other neuromuscular disorders, and eight patients with hypogammaglobulinemia but no muscle disease. The serum urate concentration was similar in all four groups. Base line urinary purine excretion was elevated in all patients with neuromuscular disease with values of $1.72 \pm 0.15$, $2.37 \pm 0.22,2.49 \pm 0.35$, and $2.60 \pm 0.48 \mu$ moles $/ 100 \mathrm{ml}$ glomerular filtration for control subjects, mild Duchenne muscular dystrophy, severe disease, and other neuromuscular diseases, respectively.

Adenine nucleotide pool turnover was measured by labeling with $\left[8^{-14} \mathrm{C} \mid\right.$ adenine and then 5 days later administering intravenous fructose. Five-day cumulative mean radioactivity excretion was elevated in mild and severe Duchenne muscular dystrophy with excretion values of $11.4 \pm 0.7$ and $11.5 \pm 1.1 \%$ of administered radioactivity, respectively, as compared to $9.0 \pm 0.9 \%$ of administered radioactivity for control subjects. After intravenous fructose infusion, patients with Duchenne muscular dystrophy had a less than normal rise in serum urate concentration, a normal increase of urinary purine excretion, and a greater than normal elevation of urinary radioactivity excretion and urinary purine specific activity. Patients with other neuromuscular diseases had virtually no rise in plasma urate concentration, less than normal increase in urinary total purine excretion, and a greater than normal increase of urinary radioactivity excretion and urinary specific activity.

These observations suggest that there is an increased rate of adenine nucleotide turnover in Duchenne muscular dystrophy. In patients with other neuromuscular disease an increased rate of adenine nucleotide turnover resembled the abnormality expected from a diminshed adenine nucleotide pool.
\end{abstract}

\section{Speculation}

The accelerated turnover of adenine nucleotides in Duchenne muscular dystrophy may result from the proposed membrane defect. Treatment directed toward increasing the synthesis of ATP may be beneficial in Duchenne muscular dystrophy.

Despite intensive research to discern the molecular basis for the progressive disorder in Duchenne muscular dystrophy, a single primary biochemical abnormality has eluded investigators. Prominent hypotheses to explain the disorder have included a structural membrane abnormality $(11,25,26,28,29,37,40)$ or an accelerated state of protein degradation in dystrophic muscle $(16,31)$. It is at present difficult to discern which of these possibilities may be correct or indeed, whether both types of disorders may result from a more fundamental abnormality in the dystrophic muscle cell.

A disorder of adenine nucleotide metabolism in Duchenne muscular dystrophy has been suggested by a reduction of high energy phosphate compounds in dystrophic muscles $(3,5,13,14$, $20,30,39)$. Allopurinol therapy increases muscle adenine nucleotide levels and improves muscular dystrophy $(34,35)$. Although the efficacy of allopurinol therapy is now doubtful $(1,4,34)$, its ability to modify purine degradation may be relevant for a possible disorder of adenine nucleotide degradation.

To clarify whether there may be a disorder of adenine nucleotide degradation in Duchenne muscular dystrophy, we have applied newly established sensitive methods for the study of purine nucleotide degradation in vivo (8) (Figure 1). The adenine nucleotide pool is labeled with radioactive adenine. Base line adenine nucleotide turnover rates are assessed independent of de novo purine synthesis by measuring urinary excretion of radioactivity. A subsequent infusion of fructose accelerates this pathway and provides a sensitive measure for the detection of disorders of nucleotide degradation. Using these methods our studies suggest a disorder of adenine nucleotide degradation in Duchenne muscular dystrophy.

\section{METHODS}

Tetrasodium phosphoribosylpyrophosphate, D-fructose, uricase, xanthine oxidase, AMP, IMP, adenine, and purine nucleoside phosphorylase were purchased from the Sigma Chemical Co., St. Louis, MO. Xanthine and hypoxanthine were purchased from Calbiochem-Boehring Corp., American Hoechst Corp., San Diego, CA. From Amersham Corp., Arlington Heights, IL we purchased $\left[8-{ }^{14} \mathrm{C}\right]$ hypoxanthine $(50 \mathrm{mCi} / \mathrm{mmole})$ and [8${ }^{14} \mathrm{C}$ linosine $(50 \mathrm{mCi} / \mathrm{mmole})$. From New England Nuclear Corp., Boston, MA, we purchased $\left[8 .{ }^{14} \mathrm{C}\right]$ adenine $(52 \mathrm{mCi} / \mathrm{mmole})$ and $\left[8-{ }^{14} \mathrm{C}\right.$ ]adenonsine $(55 \mathrm{mCi} / \mathrm{mmole})$. In line Cathivex filter units $(0.22$ and $045 \mu \mathrm{M})$ were obtained from Millipore Corp., Bedford, MA. All other reagents were of the highest quality commercially available.

Fifteen patients with mild Duchenne muscular dystrophy, eight patients with severe Duchenne muscular dystrophy, and seven patients with other neuromuscular disease (four spinal muscular atrophy, one Becker dystrophy, one congenital myopathy, and one myotonic dystrophy) were admitted to the University of Tennessee Center for Health Sciences. The category of mild Duchenne muscular dystrophy was defined as a score of 6 or below on a scale from 2 to 17 of an assay of functional activity as defined by Vignos and Licht (38) modified to include activities performed mainly with the upper extremity. Severe muscular dystrophy was defined as a score above 6 . Table 1 lists the patients in these different categories with their age and functional score. Eight patients with primary hypogammaglobulinemia and a deficiency of lymphocyte membrane 5 -nucleotidase were hospitalized on the Clinical Research Center at the University of Michigan for study of a possible disorder of purine metabolism. Careful observation of this group has revealed no evidence for a systemic 
disorder of purine metabolism (7). Plasma urate levels and urinary uric acid excretion were normal. The response to intravenous fructose was comparable to that of eight adult subjects. The patients with other neuromuscular diseases or with hypogammaglobulinemia were used for comparison with Duchenne muscular dystrophy. Patients with other neuromuscular disease resembled mild Duchenne muscular dystrophy in functional capacity and age (Table 1). The patients with hypogammaglobulinemia were older than the patients with muscle disease (Table 1). Informed consent was obtained from all adult patients and from the parents of children. Each patient received a weight maintenance purinefree diet with 10 to $12 \%$ protein for 5 days before and during the study period. No medication that alters uric acid synthesis or excretion was given.

Ten to $25 \mu \mathrm{Ci}$ of $\left[8-{ }^{14} \mathrm{C}\right.$ ]adenine contained in 2 to $5 \mu$ moles of adenine was administerd intravenously through Cathivex filters (8) (Fig. 1). The filters were flushed with $40 \mathrm{ml}$ of $0.87 \%$ sodium chloride. Daily urine collections were obtained over a 5-day period. Aliquots consisting of $0.5 \mathrm{ml}$ of each urine sample were pipetted into a scintillation vial to which was added $5 \mathrm{ml}$ of Instagel. The suspension was then counted in a Packard Model 303 liquid scintillation spectrometer system. The total amount of radioactivity excreted each day was calculated and this value was divided by the total amount of radioactivity infused to determine the percentage of excretion. Three to five days after radioactive adenine administration, all patients received fructose $(0.5 \mathrm{~g} / \mathrm{kg})$ intravenously over $10 \mathrm{~min}$ as previously described (8) (Fig. 1). Blood for plasma urate determination was obtained at $0,15,30$, 60,90 , and $150 \mathrm{~min}$ after the start of the intravenous fructose. Urine for creatinine, radioactivity, uric acid, oxypurine, and inosine was obtained at hourly intervals for $1 \mathrm{hr}$ before and $3 \mathrm{hr}$ after the fructose infusion. Hypoxanthine-guanine and adenine phosphoribosyltransferases, PP-ribose-P synthetase, purine nucleoside phosphorylase, and adenosine deaminase were determined by radiochemical methods $(9,10,18,36)$. Serum urate and urinary uric acid, oxypurines and inosine were quantitated by enzymatic spectrophotometric methods $(8,19,22)$. Creatinine was measured by an automated Jaffe reaction (33). Urinary purine excretion was expressed per $100 \mathrm{ml}$ of glomerular filtrate instead of the standard method using the urinary creatinine excretion. This minimizes the error caused by the decreased urinary creatinine excretion, which occurs in neuromuscular diseases. Protein was estimated by the method of Lowry et al. (21) with bovine serum albumin as a standard. Concentrations of compounds using these studies were based on the descriptions or assays provided by the manufacturer. Statistical studies utilized the unpaired two-tailed Student's $t$ test. Calculations were performed on a Hewlett Packard 9825 programmable desk top calculator using the statistics program package.

\section{RESULTS}

\section{BASE LINE MEASUREMENTS}

Purine nucleotide degradation was assessed by measuring the serum and urinary purines (Table 1). Serum urate concentration in these groups of patients was in the normal range for this age group. Base line urinary purine excretion expressed as $\mu$ moles $/ 100$ $\mathrm{ml}$ glomerular filtration was found to be significantly elevated in patients with mild muscular dystrophy $(P=0.03)$, severe muscular dystrophy $(P=0.03)$, and other neuromuscular diseases $(P=$ $0.04)$. Urinary uric acid excretion $(\mathrm{mg} / \mathrm{kg} \pm$ S.D.) was higher in mild Duchenne muscular dystrophy $(10.9 \pm 2.3)$ and other neuromuscular diseases $(9.4 \pm 2.6)$ than normal controls $(7.6 \pm 2.0)$ or severe muscular dystrophy $(8.5 \pm 3.4)$. Base line urinary purine excretion was also evaluated using tracer studies with [8${ }^{14} \mathrm{C}$ ]adenine which may provide a sensitive indication of the turnover of the adenine nucleotide pool (10) (Fig. 1). The 5-day cumulative radioactivity excretion was found to be significantly increased in mild and severe muscular dystrophy $(P<0.03$ and $<0.05$ ), but not in other neuromuscular diseases (Table 1). In these studies values for neuromuscular diseases were similar to those of Duchenne muscular dystrophy.

\section{ACCELERATION OF NUCLEOTIDE DEGRADATION BY FRUCTOSE}

The increased purine excretion and the elevated radioactivity excretion in Duchenne muscular dystrophy suggested that a disorder of purine nucleotide degradation may be present. To assess for this possibility, the pathway of purine nucleotide degradation was perturbed by intravenous fructose infusion. Intravenous fructose is known to cause the rapid degradation of adenine nucleotides to purine end products (Fig. 1). This results in an elevation of plasma urate concentration and in the urine a major increase in inosine excretion and smaller increases in hypoxanthine and uric acid excretions (8). The sum of these three urinary purines is referred to as total purine excretion. Altered responsiveness to intravenous fructose could indicate the nature of the disorder.

All three groups of patients with neuromuscular disease had a less than normal rise in the serum urate concentration after intravenous fructose (Fig. 2). However, the patients with other neuromuscular diseases had the smallest increase in serum urate levels. The elevation of total purine excretion during the first hour after a fructose infusion was similar in Duchenne muscular dystrophy and control subjects, but was decreased significantly in other neuromuscular diseases (Fig. 3). There was a significant difference in the purine excretion between other neuromuscular diseases and severe muscular dystrophy $(P<0.03)$, and a difference of borderline significance between other neuromuscular diseases and mild Duchenne muscular dystrophy $(P<0.06)$. Uric acid accounted for 86.1 to $89.4 \%$ of total purine excretion in all groups prior to fructose infusion. After fructose infusion the percent uric acid decreased to 47.9 to $56.2 \%$ for all groups except the other neuromuscular diseases, who had a significantly $(P<$ 0.001 ) higher relative urate excretion of $71.9 \%$ of total purine excretion. On the other hand, the increase in the radioactivity excretion after a fructose infusion was substantially higher in all patients with neuromuscular disease as compared to the control patients (Fig. 4). There was no difference between other neuromuscular disease and Duchenne muscular dystrophy.

Table 1. Study subjects ${ }^{1}$

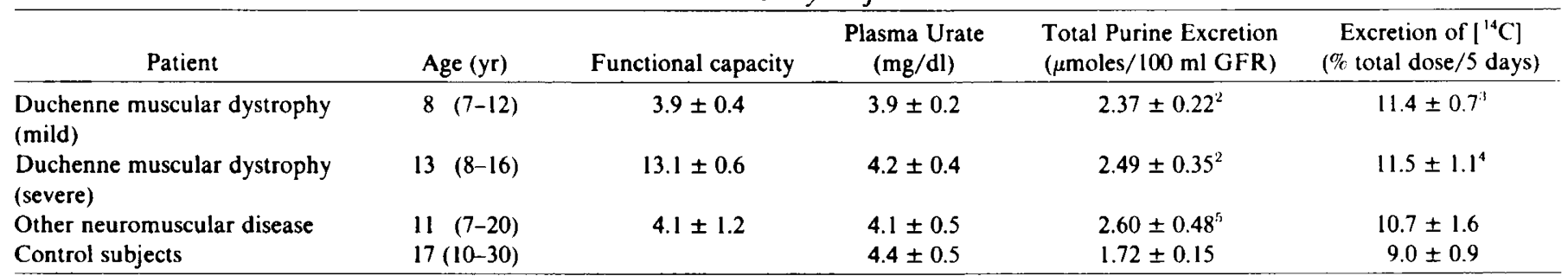

\footnotetext{
'Data are expressed as mean \pm S.E. or in the age column as mean and range.

${ }^{2} P=0.03$.

${ }^{3} P=0.03$

${ }^{4} P=0.05$.

${ }^{5} P=0.04$.
} 


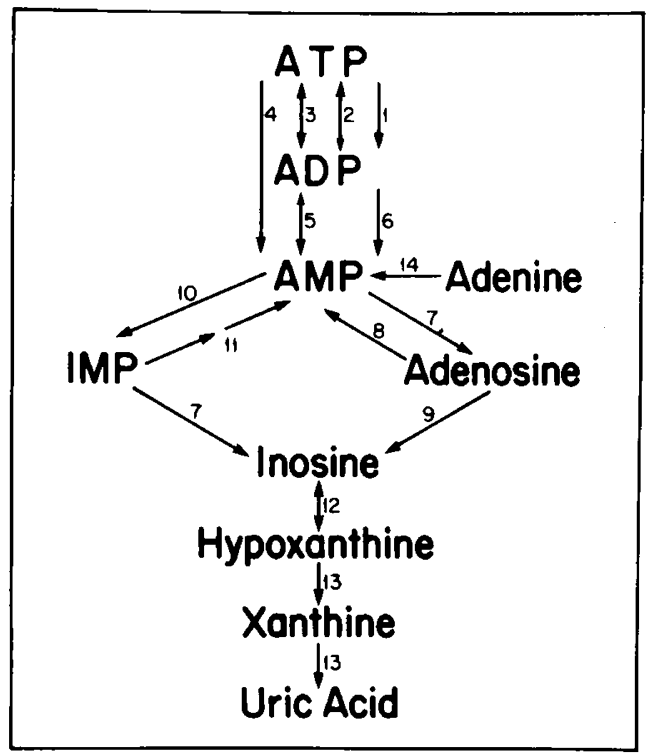

Fig. 1. Adenine nucleotide metabolism in humans. Duchenne muscular dystrophy is characterized by decreased muscle adenine nucleotides. This may be indicative of a disorder of adenine nucleotide degradation. ATP is degraded to uric acid by the pathway shown. ATP is converted to ADP by utilization in reactions of intermediary metabolism (reaction 1), nucleoside diphosphatase (reaction 1), or nucleoside disphosphate kinase (reaction 3). It may be directly converted to AMP by reactions of intermediary metabolism or nucleotide pyrophosphatase (reaction 4). ATP may be formed from ADP by creatine phosphokinase (reaction 2) or nucleoside diphsophate kinase (reaction 3). ADP may be degraded to AMP by adenylate kinase (reaction 5) or nucleoside diphosphatases (reaction 6). AMP may be either deaminated to IMP by AMP deaminase or dephosphorylated to adenosine by 5 '-nucleotidase and other phosphatases (reaction 7). Adenosine or IMP may be resynthesized to AMP (reactions 8 or 11). Inosine is formed by the deamination of adenosine by adenosine deaminase (reaction 9) or the dephosphorylation of IMP (reaction 7). Inosine is degraded to hypoxanthine by purine nucleoside phosphorylase (reaction 12), and hypoxanthine is oxidized to uric acid by xanthine oxidase (reaction 13).

When $\left[8-{ }^{14} \mathrm{C}\right]$ adenine is administered intravenously, it is removed rapidly by tissues and can be converted to AMP by adenine phosphoribosyltransferase (reaction 14). This reaction leads to the labeling of the adenine nucleotide pool. The degradation of the adenine nucleotide pool leads to a labeling of purine catabolic products.

The infusion of fructose is used as a provocative test to study the pathways of purine nucleotide degradation. Intravenous fructose activates purine nucleotide degradation by suddenly converting a large quantity of ATP to ADP during the phosphorylation of fructose. There ensues an elevated purine excretion in the urine which involves a major increase in inosine excretion and smaller increases in hypoxanthine and uric acid excretions. When the adenine nucleotide pool is radioactively labeled these urinary purines are labeled as well.

The purine nucleotide cycle of muscle includes the deamination of AMP to IMP (reaction 10) and the resynthesis of AMP from IMP (reaction 11). It is responsible for the release of ammonia by exercising muscle.

In an effort to assess the increase in radioactivity relative to the rate of purine excretion, an estimate of the specific activity of the urinary purines was made by calculating the ratio of the radioactivity excreted to the total purine excreted. In the base line period and one hour after intravenous fructose, all patients with neuromuscular disease had a significant elevation of the apparent urinary specific activity as compared to the normal value (Fig. 5).

\section{ERYTHROCYTE PURINE ENZYMES}

All patients in the study were further screened for evidence of an abnormality of purine metabolism by erythrocyte enzyme assays. The values for hypoxanthine-guanine phosphoribosyl-

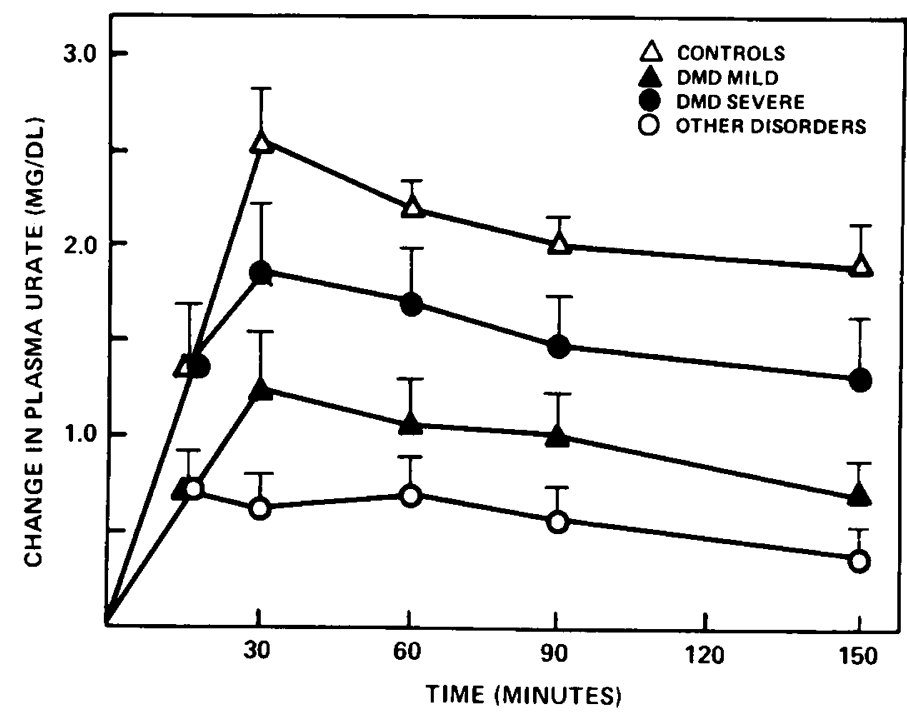

Fig. 2. Plasma urate concentration after intravenous fructose patients described in Table 1 were given intravenous fructose and the plasma urate concentration determined before and for $3 \mathrm{hr}$ afterward. The data are expressed as change in the plasma urate concentrations \pm S.E.

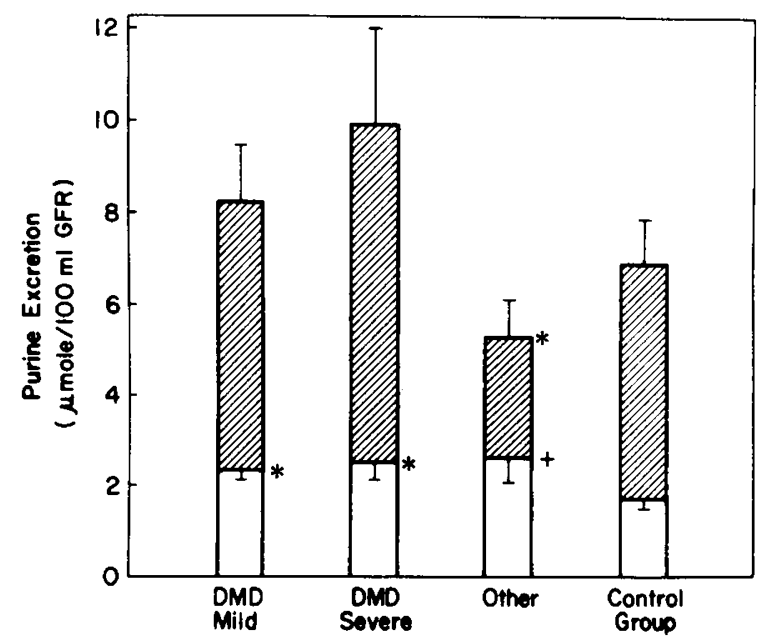

Fig. 3. Increase of purine excretion after fructose infusion in Duchenne muscular dystrophy. Urinary purines were measured for $1 \mathrm{hr}$ before ( $\square$ ) and for $\mathbf{l ~ h r}$ after the start of the fructose infusion. The increase in purine excretion after intravenous fructose is indicated ( $\square$ ). The data are expressed as \pm S.E. DMD, Duchenne muscular dystrophy; other, other neuromuscular diseases; $*, P=0.03 ;+P=0.04$.

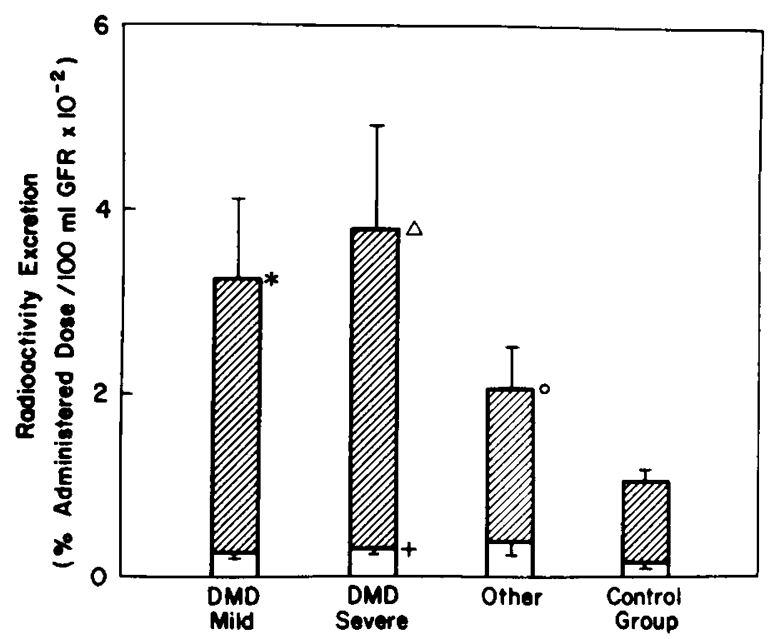

Fig. 4. Urinary radioactivity excretion after fructose infusion. Urinary radioactivity was measured as described in Figure 3. *, $P=0.05 ;+, P=$ $0.03 ; \Delta, P=0.02 ; 0, P=0.04$. 


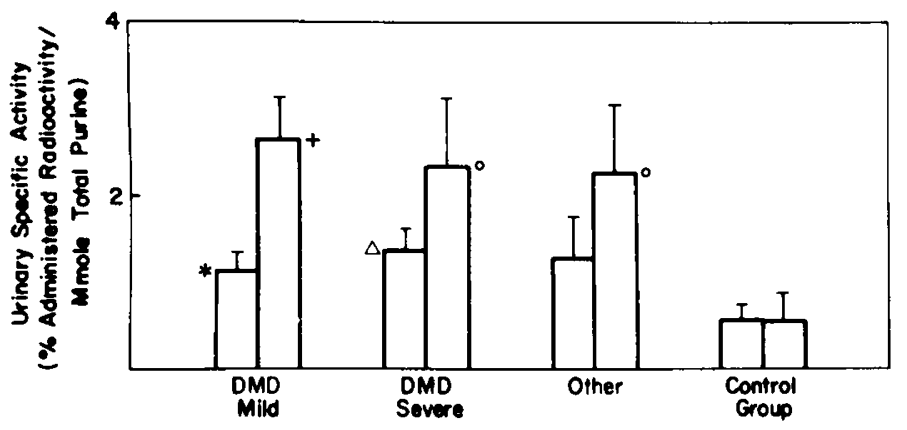

Fig. 5. Apparent specific activity of urinary purines before and after fructose infusion. The urinary apparent specific activity was estimated for $\mathrm{l} \mathrm{hr}$ before and $\mathrm{l} \mathrm{hr}$ after the intravenous infusion of fructose. The data are expressed as \pm S.E. DMD, Duchenne Muscular Dystrophy; Other, other neuromuscular diseases; $*, P=0.03 ;+, P=0.004 ; \Delta, P=0.001 ; 0$, $P=0.02$.

transferase, adenosine deaminase, purine nucleoside phosphorylase and PP-ribose-P synthetase were within the normal range.

\section{DISCUSSION}

An accelerated rate of purine nucleotide degradation may occur in muscular dystrophic syndromes. Homozygote mice for muscular dystrophy have marked elevations in the sum of uric acid and allantoin in their plasma or urine (6). Dystrophic chickens have marked elevation of the plasma urate concentrations and urinary uric acid excretion (12). An increase in de novo purine synthesis has been observed in a single patient with advanced progressive muscular dystrophy (2). Our studies of patients with Duchenne muscular dystrophy indicate a significant increase in the urinary purine excretion (Table 1).

The increase in total purine excretion observed may be related to the reduced concentrations of ATP and creatine phosphate in dystrophic muscles (Fig. 1) (3, 5, 13, 14, 20, 30, 39). ATP depletion may be to $50 \%$ of the normal value, ADP depletion to $30 \%$ of normal value and creatine phosphate depletion to $20 \%$ of the normal value. Since a diminution of muscle ATP during exercise in normal human subjects acutely increases plasma and urinary purines (32), it is evident that changes in muscle nucleotide metabolism may be detectable by sampling these body fluids. Therefore, it is possible that accelerated ATP turnover may be responsible for the increased purine excretion observed in Duchenne muscular dystrophy (Fig. 1).

Further evidence for a disorder of purine nucleotide degradation in Duchenne muscular dystrophy is suggested by the abnormal response to intravenous fructose. After fructose infusion patients with muscular dystrophy had a normal increase in total purine excretion and a significantly increased excretion of radioactivity. These data suggest that there may be a component of the adenine nucleotide pool that is degraded more rapdily after intravenous fructose. This is supported by the significantly higher apparent specific activity of the urinary purine excretion during the first hour after intravenous fructose in patients with muscular dystrophy. Although many of these changes were evident in other neuromuscular diseases suggesting elevated adenine nucleotide turnover, the latter patients were distinguished by a less than normal increase of total purine excretion and only slight elevation of the plasma urate concentration after intravenous fructose (Table 2).

Could the abnormal purine excretion observed in these diseases be related only to the decreased muscle mass and a reduction in the adenine nucleotide pool? The following changes after a fructose infusion may indicate a diminished ATP pool: little or no increase in serum urate level and urinary purine excretion, increased urinary radioactivity excretion and elevated urinary purine specific activity. Many of the biochemical alterations observed in patients with cther neuromuscular diseases (Table 2) resemble this pattern, suggesting that a diminished ATP pool may contrib-
Table 2. Alteration of purine nucleotide degration by intravenous fructose

\begin{tabular}{lccc}
\hline Measurement & $\begin{array}{c}\text { Control } \\
\text { group }\end{array}$ & $\begin{array}{c}\text { Duchenne } \\
\text { muscular } \\
\text { dystrophy }\end{array}$ & $\begin{array}{c}\text { Other neuro- } \\
\text { muscular disease }\end{array}$ \\
\hline $\begin{array}{l}\text { Plasma urate } \\
\text { Urinary purine } \\
\text { excretion }\end{array}$ & $\uparrow \uparrow$ & $\uparrow$ & $\uparrow \downarrow$ \\
$\begin{array}{c}\text { Urinary radioac- } \\
\text { tivity excretion }\end{array}$ & $\uparrow$ & $\uparrow \uparrow \uparrow$ & $\uparrow \downarrow$ \\
$\begin{array}{c}\text { Urinary purine } \\
\text { specific activity }\end{array}$ & $\uparrow \downarrow$ & $\uparrow \uparrow$ & $\uparrow \uparrow$ \\
\hline
\end{tabular}

ute to the abnormalities. Since disease severity in other neuromuscular diseases is functionally similar to mild Duchenne muscular dystrophy (Table 1), it is unlikely that this abnormality can be attributable only to more severe disease and more extensive muscle wasting. Duchenne muscular dystrophy deviates from this pattern. The normal increase in urinary total purine excretion following fructose infusion (Fig. 3) suggests that the nucleotide pool degraded in Duchenne muscular dystrophy may be similar in size to the nucleotide pool in control subjects. The observation of an abnormality common to both severe and mild Duchenne muscular dystrophy suggests that the disorder is not related only to the degree of muscle wasting and disease severity.

Although our data suggest an accelerated rate of adenine nucleotide turnover in Duchenne muscular dystrophy, the tissue origin of these abnormalities cannot be localized. Increased ATP turnover in muscle tissue from Duchenne muscular dystrophy is an interpretation compatible with these observations, but this cannot be proven without direct studies of muscle tissue. Furthermore, it is not possible to state whether this alteration is a primary abnormality in Duchenne muscular dystrophy or whether it might be secondary to some other disorder. For example, the proposed membrane dysfunction in Duchenne muscular dystrophy $(11,25$, $26,28,29,37,40$ ) could lead to depletion of ATP concentrations in muscle cells. The increased consumption of ATP to maintain cellular homeostasis could accelerate purine nucleotide turnover. Alternatively, there may be a primary disorder of ATP metabolism. This possibility is suggested by abnormal mitochondria in the liver of dystrophic mice (17). In addition, hereditary dystrophic mice have a defect of the purine nucleotide cycle in skeletal muscle (27), which may modify adenine nucleotide metabolism (Fig. 1). Finally, there is no discernable connection at present between muscular dystrophy and known inborn errors of purine metabolism, since the erythrocyte purine enzymes measured were normal. Elevation of hypoxanthine-guanine phosphoribosyltransferase has been observed in muscle tissue from Duchenne muscular dystrophy (24). The value was normal in erythrocytes in our study and in another report (24), suggesting that the elevated muscle enzyme activity may be a secondary alteration (15).

Whether an accelerated rate of purine nucleotide turnover in Duchenne muscular dystrophy is a primary or a secondary cause of the disease may not be important in terms of the potential therapy for the disorder. If ATP depletion represents an abnormality secondary to some other primary disorder, an increase in ATP concentrations in muscle cells may improve muscle function and prevent continued deterioration. Therefore, the issues of a disorder of adenine nucleotide turnover and its modification by specific therapy require further consideration in the etiology and management of Duchenne muscular dystrophy.

\section{REFERENCES AND NOTES}

1. Bakouche, P., Chaouat, D., and Nick, J.: Allopurinol not effective in muscular dystrophy. N. Engl. J. Med., 301: 785 (1979).

2. Benedict, J. D., Roche, M., Yu, T. F., Bien, E. J., Gutman, A. B., and Stetten, D., Jr.: Incorporation of glycine nitrogen into uric acid in normal and gouty man. Metabolism, 1: 3 (1952)

3. Berthillier, G., Gautheron, D., and Robert, J. M.: Fractions phosphorylees et nucleotides adenyliques libres de muscle myopathiques chez l'enfant. CR Acad. Sci. (Paris), 265: 79 (1967). 
4. Castro-Gago, M., Jimenez, J. F., Pombo, M., Tojo, R., Couselo, J. M., and Pena, J.: Allopurinol in Duchenne Muscular Dystrophy. Lancet. $l$ : 1358 (1980).

5. Collazo, J. A., Barbudo, J., and Torres, L.: Der Chemismus des Muskals bei der Dystrophia Muscularis progressiva (Analyse der Biopsie des Deltoideus). Deut. Med. Wochenchr.. 62: 51 (1936).

6. Dju, M. Y., and Yu. T. F.: Uric acid metabolism in homozygous and heterozygous muscular dystrophic mice. Am. J. Physiol.. 234: E421 (1978).

7. Edwards, N. L., Cassidy, J. T., and Fox, I. H. Lymphocyte 5'-nucleotidase deficiency in hypogammaglobulinemia: clinical characteristics. Clin. Immunol Immunopathol. 17: 76 (1980).

8. Edwards, N. L. Recker, D., and Fox. I. H.: Overproduction of uric acid in hypoxanthine-guanine phosphoribosyltransferase deficiency. Contribution by impaired purine salvage. J. Clin. Invest., 6.3: 922 (1979).

9. Fox, I. H., Andres, C. M., Gelfand, E. W., and Biggar, D.: Purine nucleoside phosphorylase deficiency; altered kinetic property of a mutant enzyme. Science, 197: 1084 (1977).

10. Fox, I. H., and Kelley, W. N.: Human phosphoribosylpyrophosphate synthetase distribution, purification, and properties. J. Biol. Chem., 246: 5739 (1971).

I1. Godin, D. V., Bridges, M. A., and MacLeod, P. J. M.: Chemical compositional studies of erythrocyte membranes in Duchenne muscular dystrophy. Res. Commun. Chem. Pathol. Pharmacol., 20: 331 (1978).

12. Hevia, P., Shaffer, R. H., Peterson, D. W., and Clifford, A. J.: Hepatic purine enzyme profiles and uric acid overproduction in muscular dystrophy and in inherited tophaceous gout. Proc. Soc. Exp. Biol. Med., 158: 332 (1978).

13. Heyck, M., Laudahn, G., and Lüders, C. J.: Fermentaktivitatsbestimmugen in der gesunder menschlichen Muskulatur und bei Myopathien. Klin Wock., 4I: 500 (1963).

14. Kar, N. C.. and Pearson. C. M.: Muscle adenylic acid deaminase activity: Selective decrease in early-onset Duchenne muscular dystrophy. Neurology. 23: 478 (1973).

15. Kar, N. C., and Pearson, C. M.: 5'-Nucleotidase activity of normal and dystrophic human muscle. Proc. Soc. Exp. Biol. Med.. 143: 1125 (1973).

16. Kar, N. C., and Pearson, C. M.: Muscular dystrophy and activation of proteinases. Muscle Nerve, I: 308 (1978).

17. Katyare, S. S., Challberg. M. D., and Howland, J. L.: Energy coupling in liver mitochondria from dystrophic mice: Differential sensitivity of oxidative phosphorylation and $\mathrm{Ca}^{2+}$ uptake to $\mathrm{K}^{+}$. Metabolism. 27: 761 (1978).

18. Kelley, W. N., Rosenbloom, F. M.. Henderson, J. F., and Seegmiller, J. E.: A specific enzyme defect in gout associated with overproduction of uric acid Proc. Natl. Acad. Sci. U.S.A., 57: 1735 (1967).

19. Klinenberg. J. R., Goldfinger, S., Bradley, K. H., and Seegmiller, J. E.: An enzymatic spectrophometric method for the determination of xanthine and hypoxanthine. Clin. Chem., 13: 834 (1967).

20. Konzoni, E., Wald, S., Berg, L., and Ramsey, R. Distribution of high energy phosphate in normal and dystrophic muscle. Neurology, 8: 359 (1958).

21. Lowry, O. H., Rosebrough. N. J., Farr. A. L.. and Randall, R. J.: Protein measurement with Folin phenol reagent. J. Biol. Chem.. 193: 265 (1951).

22. Liddle, L., Seegmiller, J. E., and Laster, L.: The enzymatic spectrophotometric method for determination of uric acid. J. Lab. Clin. Med., 54: 903 (1959).

23. Mendell, J. R., and Wiechers, D. O.: Lack of benefit of allopurinol in Duchenne dystrophy. Muscle Nerve, 2: 53 (1979).

24. Neerunjun, J. S., Allsop, J., and Dubowitz, V.: Hypoxanthine-guanine phosphoribosyltransferase activity of blood and muscle in Duchenne dystrophy. Muscle Nerve, 2: 19 (1979).

25. Pearson. T. W.: $\left(\mathrm{Na}^{+}+\mathrm{K}^{+}\right)$-ATPase of Duchenne muscular dystrophy erythro- cyte ghosts. Life. Sci., 22: 127 (1978).

26. Pickard, N. A., Hanns-Dieter, G., Verril, H. L., Isaacs, E. R., Robinow, M., Nance. W. E., Myers. E. C.. and Goldsmith, B.: Systemic membrane defect in the proximal muscular dystrophies. N. Engl. J. Med., 299: 841 (1978).

27. Sanada. H., and Yamaguchi, M.: A defect of purine nucleotide cycle in the skeletal muscle of hereditary dystrophic mice. Biochem. Biophy. Res. Commun., 90: 453 (1979).

28. Sato, B., Nishikida, K., Samuels, L. T., and Tyler, F. H.: Electron spin resonance studies of erythrocytes from patients with Duchenne muscular dystrophy. J. Clin. Invest., 61: 251 (1978).

29. Schotland, D. L., Bonilla. E., and Van Meter, M.: Duchenne dystrophy: Alteration in muscle plasma membrane structure. Science, 196: 1005 (1978).

30. Stengel-Rutkowski L., and Barthelmai, W.: Muscular energy metabolism in children with progressive muscular dystrophy type Duchenne. Metabolites of the Embden-Meyerhof pathway, the citric acid cycle and high energy phosphates and enzyme activity of alpha-glycerol-oxidase. succinate dehydrogenase and 6-phospho-gluconate-dehydrogenase. Klin. Wochenschr., 51: 957 (1973).

31. Stracher. A., McGowan. E. B., and Shafiq, S. A.: Muscular dystrophy: inhibition of degeneration in vivo with protease inhibitors. Science. 2(O): 50 (1978).

32. Sutton, J. R., Toews, C. J., Ward, G. R., and Fox. 1. H.: Purine metabolism during strenuous muscular exercise in man. Metabolism. 29: 254 (1980).

33. Technicon Auto Analyzer $R$ method file. Method N 116. Technicon Instruments Corp., Tarrytown, NY 1969.

34. Thomson. W. H. S. and Smith. I.: X-linked recessive (Duchenne) muscular dystrophy (DMD) and purine metabolism: Effects of oral allopurinol and adenylate. Metabolism, 27: I5I (1978).

35. Thomson. W. H. S., and Smith. I.: Allopurinol in Duchenne's muscular dystrophy. N. Engl. J. Med., 299: 101 (1979).

36. Van der Weyden. W. B., Buckley, R. H., and Kelley, W. N.: Molecular form of adenosine deaminase in severe combined immunodeficiency. Biochem. Biophys. Res. Commun., 57: 590 (1974).

37. Vickers, J. D., Rathbone, M. P., and Roses, A. D.: Alterations of erythrocyte ghost protein phosphorylation in the Duchenne and myotonic muscle dystrophies. Biochem. Med., 20: 434 (1978).

38. Vignos, P. J., and Licht, S.: Rehabilitation in muscular dystrophy. In: Rehabilitation and Medicine. New Haven. E. Licht, (1968).

39. Vignos, P. J.. and Warner, J. L.: Glycogen, creatine, and high energy phosphate in human muscle disease. J. Lab. Clin. Med.. 62: 579 (1963).

40. Wilkerson. L. S., Perkins, R. C., Jr., Roelofs, R., Swift, L., Dalton. L. R., and Park, J. H. Erythrocyte membrane abnormalities in Duchenne muscular dystrophy monitored by saturation transfer electron paramagnetic resonance spectroscopy. Proc. Nat. Acad. Sci. U.S.A., 75: 838 (1978).

41. The authors thank Sharon Rawley for technical assistance and Linda Christensen for typing the manuscript, and the nurses and dieticians of the Clinical Research Center at the University of Tennessee Health Sciences Center and the University of Michigan for their management of the patients.

42. Requests for reprints should be addressed to: Dr. Irving H. Fox. Clinical Research Center, University Hospital. Ann Arbor, MI 48109.

43. Dr. Edwards was a Clinical Associate Physician of the Clinical Research Center supported by USPHS 5-MOI RR42.

44. This research was supported by a grant from the Muscular Dystrophy Association. Inc., and from the USPHS 5-MOI RR42, 5-MOI RR22, and AM-19674.

45. Received for publication December 9, 1980.

46. Accepted for publication April 16, 1981. 